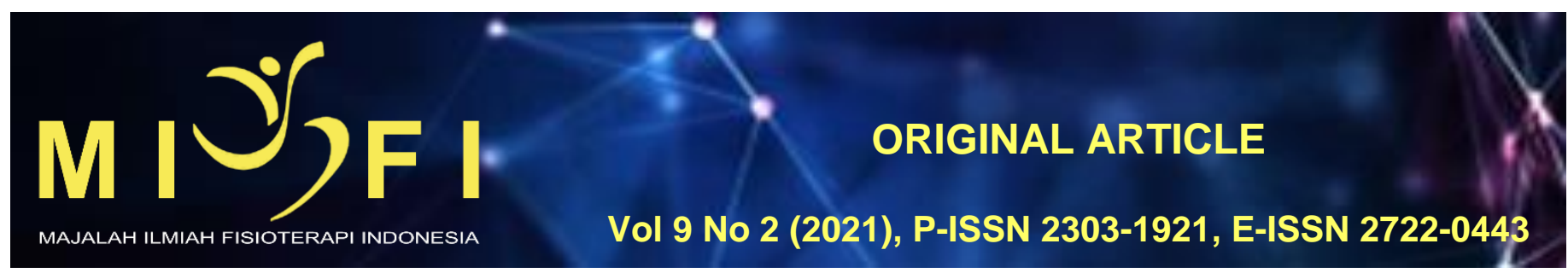

\title{
PERBEDAAN TINGGI VERTICAL JUMP PADA PEMAIN BASKET DENGAN NORMAL FOOT DAN FLAT FOOT DI DENPASAR
}

Ni Nyoman Mekar Sari ${ }^{1}$, Indira Vidiari Juhanna ${ }^{2}$, Made Hendra Satria Nugraha ${ }^{3}$, I Wayan Sugiritama ${ }^{4}$ ${ }^{1}$ Program Studi Sarjana Fisioterapi dan Profesi Fisioterapi, Fakultas Kedokteran, Universitas Udayana, Denpasar, Bali ${ }^{2}$ Departemen Ilmu Faal, Fakultas Kedokteran, Universitas Udayana, Denpasar, Bali ${ }^{3}$ Departemen Fisioterapi, Fakultas Kedokteran, Universitas Udayana, Denpasar, Bali ${ }^{4}$ Departemen Histologi, Fakultas Kedokteran, Universitas Udayana, Denpasar, Bali mekarr19@gmail.com

\begin{abstract}
ABSTRAK
Vertical jump merupakan salah satu aspek penting dalam mendukung prestasi pada pemaian basket. Vertical jump diketahui dengan mengukur tinggi lompatan yang dapat dijangkau. Vertical jump dipengaruhi oleh beberapa faktor diantaranya bentuk arkus pedis. Penelitian ini bertujuan untuk mengetahui Perbedaan Tinggi Vertical Jump pada Pemain Basket dengan Normal Foot dan Flat Foot di Denpasar. Penelitian ini merupakan penelitian cross sectional analitik dengan jumlah total sampel 54 orang. Variabel independen dalam penelitian ini adalah bentuk arkus pedisnormal foot dan flat foot yang diukur menggunakan Wet Foot Print Test, sedangkan variabel dependen dalam penelitian ini adalah tinggi vertical jump yang diukur menggunakan Vertical Jump Test. Teknik analisis data yang dilakukan yaitu uji normalitas menggunakan Kolmogorov Smirnov's Test dan uji hipotesis Independent T-Test untuk mengetahui perbedaan tinggi vertical jump pada kelompok normal foot dan flat foot. Hasil uji Independent T-Test menunjukkan nilai $\mathrm{p}=0,505$ ( $\mathrm{p}>0,05)$, hasil ini menunjukan tidak terdapat perbedaan tinggi vertical jump yang signifikan pada pemain basket dengan normal foot dan flat foot.
\end{abstract}

Kata kunci: normal foot, flat foot, vertical jump, pemain basket

\section{THE DIFFERENCES OF VERTICAL JUMP HEIGHT IN BASKETBALL PLAYERS WITH NORMAL FOOT AND FLAT FOOT IN DENPASAR}

\begin{abstract}
Vertical jump is one of the important aspects for supporting the achievements in basketball players. Vertical jumps are known by measuring the height of jumps that can be reached. Vertical jump influenced by several factors including foot arch. This study aims to determine the difference in vertical jump height in basketball players with normal foot and flat foot in denpasar. This research is a cross sectional analytic study with a sampling technique using consecutive sampling with a total sample 54. The independent variable in this study is the form of normal foot and flat foot arches measured using the Wet Foot Print Test, while the dependent variable in this study is the vertical jump height measured using the Vertical Jump Test. The data analysis technique used is the normality test using the Kolmogorov Smirnov's Test and the Independent T-Test hypothesis to determine the difference in vertical jump height in the normal foot and flat foot groups. The result of Independent T-Test showed value $p=0.505$ ( $p>0.05)$, this results showed no significant difference vertical jump height in basketball players with normal foot and flat foot.
\end{abstract}

Keywords: normal foot, flat foot, vertical jump, basketball players

\section{PENDAHULUAN}

Flat foot/pes planus merupakan kondisi yang ditandai dengan menurunnya atau menghilangnya seluruh ketinggianarcuslongitudinal medialdari kaki yang menyebabkan cekungan dari telapak kaki menjadi datar. ${ }^{1}$ Kondisi inisering merupakan akibat dari kelemahan sendi di bagian tengah atau proksimalforefoot, dan dikombinasikan dengan meregangnya ataumelemahnya plantar fascia, ligamen spring, dantendontibialis posterior. ${ }^{2}$ Flat footdapat menyebabkankontrol postur terganggu, gangguantekanan pada telapak kaki, berbagai cedera pada ekstremitas bawah, perubahan padamobilitas sendi, pergelangan kaki dan kaki. ${ }^{3}$

Arcus pedis merupakan salah satu faktor yang mempengaruhi kemampuan melompat. ${ }^{4}$ Arcus pedis didukung oleh tulang kaki, ligamen spring, plantar aponeurosis, otot plantar dan tendon. ${ }^{5}$ Ligamen spring berperan dalam memberikan elastisitas dan gaya pegas pada arcus. ${ }^{6}$ Gaya pegas yang berfungsi dengan baik akan membantu usaha dalam melakukan lompatan menjadi maksimal. ${ }^{7}$ Vertical jumpadalah salah satu keterampilan yang berperan besarbaik dalam kegiatan sehari-hari maupun dalambanyak bidang atletik dan merupakan faktor utama dalam kesuksesan di dunia atletik. ${ }^{3}$

Hubungan antara flat foot dengan vertical jump masih menjadi kontroversi saat ini. Sebuah penelitian menjelaskan mengenai hubungan antara flat foot dengan aktivitas fisik pada anak. Anak yang mengalami flat foot akan memiliki level aktivitas yang rendah. Hal ini dapat disebabkan karena anak flat foot kurang melakukan aktivitas olahraga dan latihan penguatan otot kaki seperti bermain bola, berlari, bermain basket dan sebagainya. ${ }^{8}$ 
Sebuah penelitian menjelaskan mengenai perbandingan tinggi vertical jump pada laki-laki dan perempuan dengan normal foot dan flat foot. Hasil yang didapatkan dari penelitian ini menyatakan bahwa tidak terdapat perbedaan yang signifikan tinggi vertical jump pada laki-laki dan perempuan dengan normal foot dan flat foot. ${ }^{3}$ Tujuan dari penelitian ini adalah untuk mengetahui perbedaan tinggi vertical jump pada pemain basket dengan normal foot dan flat foot.

\section{METODE}

Penelitian ini menggunakan rancangan cross sectional analitik yang terbagi menjadi dua kelompok yaitu, kelompok normal foot dan kelompok flat foot.Penelitian ini dilakukan di Sekolah Menengah Atas (SMA) Negeri 3, 4, 5, dan 8 Denpasar, pada bulan November 2019. Total jumlah sampel dalam penelitian ini sebesar 54 orang yang diseleksi dari populasi siswa yang mengikuti ekstrakurikuler basket di SMA Negeri 3, 4, 5, dan 8 Denpasar.

Sampel dipilih menggunakan consecutive sampling dengan kriteria inklusi dan eksklusi diantaranya, berusia 1518 tahun, jenis kelamin laki-laki, indeks massa tubuh kategori normal, kekuatan otot tungkai kategori baik, dan panjang tungkai sebesar 79-102 cm, tidak dalam penggunaan foot orthosis, tidak dalam kondisi pasca operasi daerah ankle serta cedera akut pada ankle.

Variabel independen dalam penelitian ini ialah normal foot dan flat foot. Vertical jump merupakan variabel dependen dalam penelitian ini. Variabel kontrol dalam penelitian ini ialah usia, indeks massa tubuh, jenis kelamin, kekuatan otot, dan panjang tungkai.

Uji normalitas data yang digunakan dalam penelitian ini adalah Kolmogorov Smirnov's Testdanuji homogenitas menggunakan Levene Test. Uji hipotesis menggunakan Independent T- Test untuk mengetahui signifikansi.

HASIL

Tabel 1. Karakteristik Subjek Penelitian

\begin{tabular}{ccc}
\hline \multirow{2}{*}{ Karakteristik } & \multicolumn{2}{c}{ Nilai Rerata \pm Simpang Baku } \\
\cline { 2 - 3 } & Normal Foot & Flat Foot \\
\hline Panjang Tungkai $(\mathrm{cm})$ & $89,10 \pm 4,10$ & $90,70 \pm 3,03$ \\
Kekuatan Otot $(\mathrm{kg})$ & $116,48 \pm 6,90$ & $116,74 \pm 6,32$ \\
\hline
\end{tabular}

Berdasarkan Tabel 1. diketahui bahwa nilai rerata panjang tungkai dan simpang baku kelompok normal foot sebesar $(89,10 \pm 4,10)$, kelompok flat foot $(90,70 \pm 3,03)$. Nilai rerata kekuatan otot dan simpang baku kelompok normal foot sebesar (116,48 $\pm 6,90)$, kelompok flat foot sebesar $(116,74 \pm 6,32)$.

Tabel 2. Uji Normalitas dan Homogenitas

\begin{tabular}{ccc}
\hline Variabel & p. Normalitas (Kolmogorov Smirnov's) & p. Homogenitas (Levene Test) \\
\hline Vertical Jump & 0,83 & 0,82 \\
\hline
\end{tabular}

Berdasarkan Tabel 2. diketahui hasil uji normalitas menggunakan Kolmogorov Smirnov's Test nilai probabilitas $p$ $=0,83$ dimana nilai $(p>0,05)$ yang berarti data tinggi vertical jump berdistribusi normal karena memiliki nilai $p>0,05$. Uji homogenitas dilakukan dengan Levene Test. Uji ini bertujuan untuk mengetahui data bersifat homogen atau tidak dan digunakan juga sebagai prasyarat untuk melakukan uji hipotesis. Berdasarkan Tabel 2 diketahui nilai probabilitas $p=$ $0,82(p>0,05)$. Hasil nilai $p>0,05$ menunjukan bahwa data bersifat homogen.

Tabel 3. Uji Beda Rerata Tinggi Vertical Jump Pemain Basket

\begin{tabular}{ccc}
\hline Kelompok & Rerata \pm SB & $\mathrm{P}$ \\
\hline Normal foot $(\mathrm{cm})$ & $39,8129 \pm 6,856$ & 0,505 \\
Flat foot $(\mathrm{cm})$ & $38,5391 \pm 6,936$ & \\
\hline
\end{tabular}

Berdasarkan data pada Tabel 3. analisis yang dilakukan dengan menggunakan Independent $T$ - Test didapatkan nilai probabilitas $p=0,505$ ( $p>0,05$ ). Hal ini menunjukkan bahwa tidak terdapat perbedaan tinggi vertical jump yang signifikan pada kelompok normal foot dan flat foot.

\section{DISKUSI}

\section{Karakteristik sampel penelitian}

Hasil penelitian menunjukan sampel berjumlah 54 orang yang berjenis kelamin laki-laki. Sampel dalam penelitian ini merupakan siswa yang mengikuti ekstrakurikuler basket dengan usia 15-18 tahun. Kekuatan otot laki-laki sedikit lebih kuat daripada kekuatan otot perempuan pada usia 10-12 tahun. Perbedaan kekuatan yang signifikan terjadi seiring pertambahan umur, di mana kekuatan otot laki-laki jauh lebih kuat daripada wanita. Pengaruh hormon testosteron memacu pertumbuhan tulang dan otot pada laki-laki, ditambah perbedaan pertumbuhan fisik dan aktivitas fisik wanita yang kurang juga menyebabkan kekuatan otot wanita tidak sebaik laki-laki. ${ }^{9}$

Seluruh sampel pada penelitian ini memiliki nilai kekuatan otot kategori baik dengan nilai rerata kekuatan otot tungkai pada kelompok normal foot yaitu $(116,48 \pm 6,90)$, dan pada kelompok flat foot yaitu $(116,74 \pm 6,32)$. Kekuatan otot adalah kemampuan otot atau grup otot menghasilkan tegangan dan tenaga selama usaha maksimal baik secara dinamis maupun statis. ${ }^{10}$ Pemain basket sering melakukan latihan secara rutin, yang menyebabkan terjadinya peningkatan aktivitas otot, meningkatnya aktivitas otot dapat menimbulkan peningkatan kekuatan otot. ${ }^{11}$

Hasil penelitian terkait variabel panjang tungkai, nilai rerata panjang tungkai pada kelompok normal foot yaitu $(89,10 \pm 4,10) \mathrm{cm}$, dan pada kelompok flat foot yaitu $(90,70 \pm 3,03)$. Panjang tungkai meningkatkan kemampuan untuk memproduksi anaerobic power, oleh karena itu meningkatkan tinggi lompatan vertikal. ${ }^{12}$ Efek ini terjadi karena posisi pusat massa tubuh dengan panjang tungkai. Panjang tungkai yang relatif lebih tinggi akan menghasilkan daya ledak otot yang lebih besar dan jarak yang lebih jauh saat melompat. ${ }^{13}$ 


\section{Perbedaan Vertical Jump pada Kelompok Normal Foot dan Flat Foot}

Flat foot merupakan kondisi yang ditandai dengan menurunnya atau menghilangnya seluruh ketinggianarcus longitudinal medialdari kaki yang menyebabkan cekungan dari telapak kaki menjadi datar. ${ }^{1}$ Flat foot atau arkus yang rata menyebabkan pedis bagian tengah atau midfoot menjadi tidak stabil dan terjadi kelemahan pada bagian midfoot sehingga menyebabkan bagian ibu jari lebih mengkompensasi ketika bergerak. ${ }^{14}$ Teori memprediksi bahwa seseorang dengan kondisi flat foot mengalami kelemahan sendi dibagian tengah atauproksimal forefoot, meregang dan melemahnya plantar fascia, ligamen spring, dan tendon tibialis posterior. Melemahnya ligamen spring akan mempengaruhi gaya pegas pada arcus sehingga mempengaruhi hasil lompatan. ${ }^{2}$ Namun, hasil penelitian ini tidak sesuai dengan teori yang ada, dimana hasil yang didapatkan tidak menunjukan adanya perbedaan tinggi vertical jump yang signifikan pada kelompok normal foot danflat foot.

Penelitian yang selaras dengan hasil penelitian ini yaitu penelitian yang dilakukan pada tahun 2018 oleh Sajedi et al, yang meneliti tentang perbandingan tinggi vertical jump pada laki-laki dan perempuan dengan normal foot dan flat foot. Hasil yang didapatkan dari penelitian ini menyatakan bahwa tidak terdapat perbedaan yang signifikan tinggi vertical jump pada laki-laki dan perempuan dengan normal foot dan flat foot. Hal ini dapat disebabkan karena flat foot sendiri mungkin tidak menyebabkan penurunan kinerja atletik tetapi komplikasi flat foot mempengaruhi kinerja. ${ }^{3} \mathrm{Flat}$ foot dengan kelainan bentuk kaki lainnya seperti hallux valgus dapat menyebabkan rasa sakit dan mobilitas berkurang. Usia subyek yang rendah, mungkin masih menyebabkan komplikasi lain dari kelainan bentuk kaki datar, sehingga kinerjanya tidak terpengaruh. ${ }^{4}$

Menurut Tudor (2013) yang meneliti hubungan antara tinggi arkus pedis dengan kemampuan motorik. Hasil penelitian ini menyatakan bahwa tidak terdapat korelasi yang signifikan antara tinggi arkus pedis dengan kemampuan motorik. Penelitian ini menyatakan bahwa hasil pengukuran kinerja atletik di semua kelompok adalah serupa dan tidak tergantung pada morfologi kaki, karena tidak ada pengaruh signifikan dari flat foot dan kemampuan motorik. ${ }^{15}$

Penelitian yang dilakukan (Petrovic, 2013) yang meneliti tentang hubungan kemampuan melompat dengan bentuk kaki. Hasil dari penelitian ini yaitu tidak terdapat perbedaan yang signifikan secara statistik antara indikator kemampuan melompat dan bentuk arkus pedis. Namun tidak berarti bahwa kaki bukanlah penghubung penting dalam menyelesaikan tugas motorik. ${ }^{16}$

Vertical jump sangat dipengaruhi oleh kekuatan otot, otot yang dominan tidak hanya otot pada kaki. Otot utama yang terlibat dalam melakukan vertical jump antara lain latissimus dorsi, erector spinae, vastus medialis, rectus femoris dan tibialis anterior. Otot latissimus dorsi dan erector spinae adalah otot tubuh yang menyebabkan gerakan meloncat menjadi optimal. ${ }^{17}$ Pemain basket rutin melakukan latihan penguatan otot yang menyebabkan pemain basket memiliki aktivitas otot yang lebih tinggi dibandingkan pada orang yang tidak terlatih. Pemberian latihan seperti isometric excercises mampu meningkatkan vertical jump, latihan isometric melatih kekuatan otot dan stabilisasi sendi secara perlahan sehingga dengan intensitas yang maksimal dan dikontrol akan sangat baik dalam menunjang peningkatan tinggi lompatan. ${ }^{18}$ Kekuatan otot tungkai menjadi salah satu variabel yang dikontrol dalam penelitian ini, dengan dikontrolnya variabel kekuatan otot tungkai mungkin menjadi salah satu penyebab hasil penelitian ini didapatkan tidak adanya perbedaan tinggi vertical jump yang signifikan pada kelompok normal foot dan flat foot, oleh karena variabel ini memiliki pengaruh yang cukup besar terhadap vertical jump.

Panjang tungkai berkontribusi secara signifikan dengan tinggi lompatan, yang menunjukkan bahwa parameter antropometri dapat dikaitkan secara erat dengan tinggi lompatan. Efek ini terjadi karena posisi pusat massa tubuh dengan panjang tungkai. Perbedaan tinggi lompatan setiap individu bisa saja terkait dengan variabel morfologi, seperti panjang tungkai yang relatif lebih tinggi, yang akan menghasilkan output daya ledak otot yang lebih besar dan jarak yang lebih jauh untuk mempercepat saat melompat. ${ }^{13}$ Penelitian ini dilakukan pada pemain basket dimana variabel panjang tungkai telah dikontrol, hal ini mungkin menjadi penyebab hasil penelitian ini tidak signifikan berbeda antara tinggi vertical jump pada kelompok normal foot dan flat foot.

Teknik sampling dalam penelitian ini menggunakan teknik consecutive sampling. Kelemahan teknik ini yaitu, hasil yang diperoleh dapat memunculkan bias dalam pengambilan keputusan. Selain itu peluang berpartisipasi tidak sama untuk semua subyek dalam populasi target yang memenuhi kriteria penelitian. ${ }^{19}$

Penelitian ini belum memberikan perbedaan yang signifikan secara statistik mengenai vertical jump pada kelompok normal foot dan flat foot, namun tidak berarti bahwa arkus pedis bukan merupakan indikator yang penting dalam motor task. Pencegahan cedera pada kaki dan ankle joint harus dilakukan dengan membentuk arkus dan memperkuat otot-otot tungkai, tendon serta ligamen karena flat foot dapat menyebabkan serangkaian masalah mulai dari knee, hip, dan spine. Pencegahan dan diagnosa menjadi hal yang penting untuk menghindari terjadinya deformitas. ${ }^{6}$

\section{KETERBATASAN PENELITIAN}

1. Peneliti tidak dapat mengontrol aktivitas fisik responden.

2. Peneliti tidak dapat mengontrol frekuensi dan berat latihan masing-masing sampel.

\section{SIMPULAN}

Tidak terdapat perbedaan antara tinggi vertical jump pemain basket dengan normal foot dan flat foot dengan nilai $p=$ 0,505

\section{DAFTAR PUSTAKA}

1. Atamturk, D. 2009. Relationship of Flatfoot and High Arch with Main Anthropometric Variables. Acta Orthop Traumatol Turc, 43(3):254-259. 
2. Neumann, A. 2010. Kinesiology of The Musculoskeletal System : Foundation of Rehabilitation. London: Mosby Elsevier

3. Sajedi, H., Salari, N., Alanag, S. A., and Akalan, C. 2018. Comparison Of Vertical Jumping Height In Primary School Boys And Girls With And Without Flat Foot. Sport Science, 7-10.

4. Hu, Y. 2016. The Relationship Between Foot Arch Height and Two-legged Standing Vertical Jump Height in Male College-age Students. Beijing Sport University.

5. Lizis,P., Posadzki,P., Smith, T. 2010. Relationship Between Explosive Muscle Strength and Medial Longitudinal Archof the Foot. Foot \& Ankle International, 31 (9): 815-822.

6. Ridjal, A. I. 2016. Perbandingan Kekuatan Otot Tungkai Antara Normal Foot Dan Flat Foot Pada Atlet Basket.Makassar: Universitas Hasanuddin Makassar

7. Nurohman, M. A., Moerjono, S., \& Basuki, R. 2017. Hubungan Tinggi Lompatan Dan Bentuk Arcus Pedis Dengan Kejadian Sprain Pergelangan Kaki Pada Atlet Bulutangkis Yang Melakukan Jumping Smash.Semarang: Universitas Muhhamadiyah Semarang.

8. Jasrin, C. J., Mayasari, W., Rakhmilla, L. E. 2016. 'Relationship between Physical Activity and Age on Flatfoot in Children'. Althea Medical Journal. 3(3): 396-400

9. Widyaratni, A. A. 2016. Penambahan Contrax Relax Stretching Lebih Efektif Daripada Ballistic Stretching Pada Latihan Depth Jump Terhadap Peningkatan Vertical jump Atlet Basket SMA (SLUA) Saraswati 1 Denpasar. Denpasar: Universitas Udayana.

10. Mulyono, R. W. 2013. Pengaruh Leg Press Terhadap Peningkatan Tinggi Lompatan (Vertical Jump)Pada Pemain Badminton. Surakarta: Universitas Muhammadiyah Surakarta

11. Motik D.N., Andayani. N. L., Juhanna. I. V., Sutadarma. I. W. 2019. Perbedaan Latihan Nordic Walking dan Latihan Berjalan Konvensional Terhadap Perubahan denyut Nadi Istirahat pada Lansia di Kecamatan Kuta Selatan, Kabupaten Badung. Majalah IImiah Fisioterapi Indonesia. 7(2):5-8

12. Hawley, S. S. 2016. The Relationship Between Foot Anthropometry and Jump Performance.United State: Appalachian State University.

13. Achmad, M. F. 2018. Hubungan Panjang Tungkai Dengan Tinggi Lompatan Pemain Basket Sekolah Menengah Atas Di Surakarta.Surakarta : Universitas Muhhamadiyah Surakarta.

14. Trisnadewi, K. A. 2018. Hubungan Tipe Arkus Pedis terhadap Risiko Terjadinya Hallux Valgus Pada Anak Sekolah Menengah Pertama Negeri 1 Sukawati Gianyar. Denpasar: Universitas Udayana.

15. Tudor, A., Ruzic. L., Sestan, B., Sirola, L. 2013. Flat-Footedness Is Not a Disadvantage for Athletic Performance in Children Aged 11 to 15 Years. Pediatrics. 123(3):e386- e392

16. Petrovic M., Obradovic, B., Peric, D. G., Bubanj, S. 2013. Jumping Abilities Are Not Related to Foot Shape. Physical Education and Sport. 11( 3):299-305

17. Nasuka., Priambodo E. N. 2017. Hubungan Panjang Lengan dan Panjang Tungkai dengan Kemampuan Vertical Jump, Spike Jump Reach dan Block Jump Reach Remaja Putra. Jurnal Media IImu Keolahragaan Indonesia. $7(1): 35-38$

18. Aprianti, N. D. 2016. Perbedaan Pengaruh Countermovement Jump Dengan Isometric Hip Flexion Excercises Terhadap Peningkatan Vertical Jump Pada Pemain Bulutangkis. Yogyakarta: Universitas 'Aisyiyah Yogyakarta

19. Sugiarto., Siagian, D., Sunaryanto, L. T., Oetomo, D. S. 2001. Teknik Sampling. Jakarta: PT. Gramedia Pustaka Utama. 